\title{
ISLAM MATARAMAN DAN ORIENTASI POLITIKNYA DALAM SEJARAH PEMILU DI INDONESIA
}

\begin{abstract}
Abdul Chalik*
Abstract: This paper deals vith a altural fraction of theJavanese Musim called Islam Mataraman HistoricallyIsamMataraman orignatedfrom theIsam that flamished during theera of theMataramKingdominaninlandJavan eseisland Thispapertriestoexplorethe uniquedharaders of this grap of the JavaneseMusims that distingiish themframothes alturally and politically. It maintains that Idam Mataraman is not only about alture, pditics or bdief, but alsoabout theintegration betweenthemall. Integrationisthekeywordin thispaper. Thepaperalsotriestoshow that inintegration process, religionisnot alvaysthekey playe. In fact wearenot interested in disaussing thewimer and thelooser in this process We areratherinterestedinshoving that theintegrationis uniqueandcomplicatedprocess, and that Idamin this part of Java is a pefeet modd of howreligon, altureand pditics can canverge withat therebeinga senseof domnation or marginalization Tocarryoutitstask, thepaper will consult not only thelocal authonitative shdars in this fied, but also theintemational expertssoastohaveabalanced viewof theprodlem At theend, wewill alsotrytodisausshow this integration imply on the political attitudes of the MusimMataraman
\end{abstract}

Keywords: IslamMataraman, Integration, pditical attitude

\section{Pendahuluan}

Jawa adalah etnik terbesar di A sia Tenggara. Etnik ini berjumlah kurang lebih empat puluh persen dari dua ratus juta penduduk Indonesia. Seperti sebagian besar penduduk Indonesia, 85 \% lebih juga memeluk agama Islam. Tetapi sudah bisa diduga, pemeluk agama yang sedemikian masif itu, berbeda-beda secara kultural, bukan karena keanekaragaman yang begitu besar di kalangan orang Indonesia, tetapi juga karena variasi subkultur di lingkungan orang Jawa sendiri. Sejak dulu mereka mengenal dua arus besar komitmen keberagamaan; yaitu mereka yang shalat dan mereka yang tidak. "Shalat" berarti menjalankan sembahyang lima waktu. O rang-orang yang melakukannya disebut "putihan", yaitu orang yang murni beragama yang ditandai dengan menjalankan shalat lima waktu secara sunguhsungguh. ${ }^{1}$ Tetapi ada juga yang disebut "abangan", yaitu mereka yang hanya menjalankan shalat ketika sempat, atau terlihat sebagai manusia beragama ketika ada peringatan harihari besar Islam, seperti idul fitri, sementara di lain hari itu, agama hanya menempel di KTP saja. Salah satu etnis terbesar ini berada di Jawa Timur.

Salah satu satu bagian dari Islam Jawa dikenal dengan sebutan Mataraman. Secara kultural, Mataraman adalah identifikasi terhadap masyarakat Jawa yang berada di bawah kekuasaan Kerajaan Mataram Islam. Antara budaya Jawa, kerajaan dan Islam terintegrasi dalam kehidupan sosial dan religius masyarakat setempat yang menandai adanya karakteristik yang khas dan berbeda dibandingkan dengan masyarakat muslim lainnya. Bukan sekedar masalah religiusitas, integrasi budaya dan agama tersebut berimplikasi pada sikap dan pola

\footnotetext{
* D osen Fakultas Ushuluddin dan Pascasarjana IAIN Sunan Ampel

${ }^{1}$ Niels Mulder, MistisismeJama;Idedog di Indonesia ter. Noor Cholis (Yogyakarta:LkiS, 2001), 7. Lihat pula Niels Mulder, RuangBatinMasyarakatIndonesia, ter. Wisnu Hardana (Yogyakarta:LKiS, 2001), 43.
} 
kehidupan politiknya. Artikel ini akan mengkaji aspek ontologis budaya Jawa dan Islam dan proses integrasinya ke dalam sub budaya Mataraman, serta bagaimana implikasi budaya tersebut terhadap sikap dan partisipasi politiknya.

\section{Memahami Jawa dan Mataraman}

Tradisi Jawa, "Jawanisme" atau "Kejawen"2, bukanlah suatu katagori religius. Namun ia lebih merujuk pada sebuah etika atau sebuah gaya hidup yang dilhami oleh pemikiran Jawa. Sehingga, ketika sebagian orang mengungkap kejawaan mereka, pada hakikatnya hal itu adalah suatu karakteristik yang secara kultural condong pada kehidupan yang mengatasi keanekaragaman religius. Pengalaman Mulder ketika melakukan penelitian di Yogyakarta, ia menemukan seorang muslim yang taat menjalankan ibadah sesuai dengan syariat Islam, tetapi mereka tetap orang Jawa yang membicarakan mitologi wayang, atau menafsirkan shalat lima waktu sebagai pertemuan pribadi dengan Tuhan. Banyak diantara mereka menghormati sametan sebagai mekanisme integrasi sosial yang penting, atau sangat memuliakan ziarah makam orang tua dan leluhur mereka. ${ }^{3}$

Apa yang dikemukakan Mulder, juga diperjelas oleh Woodward. D alam penelitiannya tentang Islam Jawa ditemukan beberapa aspek penting yang membedakan Islam Jawa dengan praktik Islam lain. Petama, Islam Jawa mengharuskan agar ritus-ritus peralihan kehidupankhitanan, perkawinan, dan kematian - harus dilaksanakan sesuai dengan hukum Islam, tetapi juga berpegang pada aspek lain dari kesalehan syariat-centris yang merupakan suatu hal yang bebas pilih. Di dalam hal ini, penerpaan mikrokosmos/ makrokosmos ke dalam pemikiran kosmologis, keagamaan, politik dan sosial mentransformasikan watak mistisisme sufi. Di Jawa, struktur jalan mistik memainkan peran dominan dalam pemikiran kosmologis sosial, politik dan tradisional.

Keelua, baik Islam normatif ${ }^{4}$ maupun berbagai versi desa Islam Jawa berkaitan dengan kepercayaan kraton (royal alt). Hubungan antara syariat dan doktrin mistik adalah suatu tema paling penting dalam teks-teks keagamaan yang menjadi dasar agama kraton. Tetapi ada kalanya Islam normatif sesuai dengan syariat, tetapi ada pula syariat tidak terpakai kesemuanya $^{5}$

Pandangan serupa juga dikemukakan oleh Muhaimin yang mengkaji Islam dalam konteks lokal. Dalam kajiannya terhadap Islam di Cirebon melalui pendekatan alternatif, ditemukan bahwa Islam di Cirebon adalah Islam bernuansa khas, yaitu Islam yang yang melakukan akomodasi dengan tradisi lokal. Ada proses tarik menarik bukan dalam bentuknya

\footnotetext{
${ }^{2}$ Ibid. 8.

${ }^{3}$ Ibid.

${ }^{4}$ Secara terminologis, Islam normatif dipahami sebagai katagori Islam yang bersumber dari wahyu setelah melalui proses peramuan, pembakuan dan telaahan lewat pendekatan dotrinal-teologis. Amin Abdullah, "Pengantar", dalam M. Amin A bdullah, Stud Agama;Nomativitasatau Historistas(Y ogyakarta:Pustaka Pelajar, 1996), v. Mark Woodward dalam penelitian di Jogyakarta, sering menyebut masyarakat yang menjalankan ajaran Islam sesuai dengan pedoman al-Qur'an dengan sebutan Islam normatif (ia sebut kesalehan normatif) sebagai lawan dari masyarakat muslim yang menggabungkan antara ajaran Islam dengan tradisi Kejawen (Islam kebatinan). Lihat Mark R. Woodward, IsamJana KesalehanNomatif, 120-6.

${ }^{5}$ Pandangan ini kemudian menjadi salah satu pijakan dalam tesis Woodward ketika melakukan penelitian teksteks kuno kraton yang terkait dengan ajaran filosofi dan ajaran agama. Lihat Mark R. Woodward, IsamJava KesalehanNomatif, 10.
} 
saling mengalahkan atau menafikan. Tetapi dalam proses saling memberi dalam koridor saling menerima yang dianggap sesuai. Islam tidak menghilangkan tradisi lokal Jawa selama tradisi tersebut tidak bertentangan dnegan Islam murni, akan tetapi Islam tidak membabat habis tradisi lokal yang masih memiliki relevansi dengan tradisi Islam. ${ }^{6}$

Meski tidak ada keraguan bahwa ide-ide kgjamenpaling cocok diekspresikan oleh mereka yang sangat terdidik dalam keluhuran budaya Jawa, dan benar pula jika Jawanisme ini paling pas elite keraton kuno atau elit yang berorientasi pada pemerintah dan keturunanya yang disebut priyayi, tetapi perlu dijernihkan bahwa kesadaran akan budaya mereka sendiri adalah fenomena yang tersebar luas di kalangan orang Jawa. Keadaan kultural ini sering berlaku sebagai sumber kebanggan diri. Orang-orang yang melestarikan budaya Jawa dengan sungguh-sungguh dianggap sebagai orang kgiamen

Dari persoalan inilah memang tidak mudah mengidentifikasi budaya Mataraman. Terlebih lagi ketika mengidentifikasi Islam Mataraman., karena sangat terikat oleh persoalan historis-genealogis, etnografis, geopolitik dan geokultural. Hal ini disebabkan oleh minimal tiga hal. Petama, bahwa pendukung atau pemangku budaya Mataraman - yang secara umum disebut etnik atau budaya Jawa - kini tersebar secara luas, akibat kebijakan politik pemerintah kolonial dan pemerintah Indonesia melalui transmigrasi, mereka menyebar ke daerah lain selain Jawa (khususnya Jawa Timur). Pada akhirnya, pengertian yang bertolak dari historis, geopolitik dan geokultural Jawa - terutama - sudah tidak mampu merangkum seluruhnya. Sebagai contoh, pengertian yang bertolak dari sejarah, geopolitik dan geokultural Kerajaan Mataram Islam atau Surakarta sudah tidak mampu merangkum fenomena budaya Mataram. Keedua, bertahan dan kuatnya pandangan yang melihat budaya Mataraman menurut satuan waktu tertentu dan satuan wilayah tertentu. Hal ini mengakibatkan timbulnya pandangan bahwa yang dimaksudkan dengan budaya Mataraman terbatas pada budaya yang berkembang sebelum terbentuknya negara Indonesia pada wilayah-wilayah utama atau lingkaran konsentris kerajaan Mataram. Keiga, budaya Mataram secara terus menerus berproses, berdialektika, berdinamika, atau berubah sosok seiring dengan perubahan dan perkembangan spasial, demografi, sosial dan ekonomi.7

Siapa sebenarnya yang disebut kejawen? Secara antropologis suku bangsa Jawa adalah orang-orang yang secara turun temurun menggunakan bahasa Jawa dengan berbagai dialeknya dalam kehidupan sehari-hari, dan bertempat tinggal di Jawa Tengah atau Jawa Timur serta mereka yang berasal dari dua daerah tersebut. Secara geografis, batas-batas Jawa, sebelah Barat adalah sungai Cilosari dan Citanduy yang dihuni oleh suku Sunda. Sedangkan sebelah timur kedua sungai tersebut disebut tanah Jawa, yaitu daerah yang didiami suku bangsa Jawa. Daerah tersebut meliputi Jawa Tengah dan Jawa Timur. Suku bangsa Jawa asli atau pribumi hidup di daerah pedalaman yaitu daerah-daerah yang secara kolektif sering disebut kganen D aerah itu meliputi Banyumas, Kedu, Yogyakarta, Surakarta, Madiun, Nganjuk, Malang dan Kediri. ${ }^{8}$

\footnotetext{
${ }^{6}$ Nur Syam, "Islam Pesisiran dan Islam Pedalaman;Tradisi Islam di Tengah Perubaha Sosial”, (Makalah tidak diterbitkan), www.ditpertais.net/

${ }^{7}$ Djoko Saryono, "Budaya Mataraman:Mencari Definisi dan Karakteristik", dalam Ayu Sutarto, Setya Yuwana Sudikan (ed.), Pentaan Kebudayaan Propinsi Jawa Timr;Ssauah Upaya Pencanian Nilai-Nilai Positif (Jember:Biro Mental Propinsi dan KompyawisdaJatim, 2008), 26.

${ }^{8}$ Herusatoto, SimbdismedalamBudayaJava, 42.
} 
Sementara yang termasuk budaya Mataraman di Jawa Timur adalah;(1) budaya yang dipangku, dipeluk, dan diikuti oleh manusia Jawa (etnik Jawa) yang tersebar luas di berbagai wilayah Jawa Timur;(2) Budaya yang secara genealogis-geografis pada mulanya tumbuh dan berkembang di wilayah kerajaan Mataram dan kemudian menyebar ke berbagai daerah di Jawa Timur; dan (3) Yang secara historis mencakup masa Islam sampai dengan masa Indonesia moderen. ${ }^{9}$

Banyak hal yang membedakan antara budaya Jawa dan non-Jawa. D alam tata laksana hidup, masyarakat Jawa mengenal apa yang disebut dengan filsafat hidup. Filsafat Jawa terbentuk dari penggabungan alam pikir Jawa tradisional, kepercayaan Hindu atau Buddha, ajaran filasat India dan mistisisme Islam. Pandangan tersebut banyak ditemuai dalam karya sastera atau puisi yang ditulis oleh seniman keraton. ${ }^{10}$

Filsafat hidup orang Jawa adalah; pertama, berikhtiar untuk membuka jalan pengertian yang tertutup misteri ke arah kejelasan realitas. Kedua, berfikir sedalam-dalamnya setiap gejala yang akan dipermasalahkan, agar sampai pada kesimpulan yang bersifat umum dan universal. Ketiga, mencari kejelasan antara hubungan sebab-akibat. Keempat, dengan menggunakan suatu sistem dan metode. Kelima, memecahkan masalah dan mencari tujuan. ${ }^{11}$ Sementara dasar masyarakat Jawa adalah masyarakat kekeluargaan, gotong royong dan berketuhanan. ${ }^{12}$

Munculnya kelompok elite Islam di Jawa yang berusaha memasukkan ajaran "Islam dalam tradisi Jawa" tidak lepas dari peranan Sultan Agung. Ketika kerajaan Islam pesisir, D emak yang syariah-centris mulai kehilangan pengaruh dan akhirnya jatuh, Sultan Agung dengan segala kemampuannya berusaha untuk mendapatkan pengaruh dari kalangan Islam dan Jawa dengan memasukkan unsur-unsur mistis ke dalam Islam. Tradisi babad dibangun dan dimasukkan untuk menegarkan legitimasi keagamaan Sultan Agung. Dalam hal ini, terutama BabadNitik SultanAgungsangat penting. Babadtersebut menggambarkan kepandaian keagamaan dan kemampuan magis Sultan Agung. Hal ini termasuk penaklukan kerajaan Sumatera dan Mekkah secara magis. Imogiri dilukiskan sebagai Mekkahnya Jawa dan tempat pemakaman Iskandar Agung. Sultan Agung dikatakan mempunyai kemampuan terbang dan shalat jum'at rutin di Mekkah. ${ }^{13}$ Bahkan penggunaan gelar susuhuman dan sultanadalah upaya untuk menempatkan mandat keagamaannya. Susuhuman pada waktu itu, hanya disandang, terutama oleh para pemimpim agama. G elar sultandiberikan kepadanya oleh ulama' Mekkah tahun $1641 .^{14}$

Kendati penerimaan dan penulisan teks-teks babad memperkokoh klaim-klaim keagamaan mengenai pentingnya kekerabatan, tetapi hal itu memperlihatkan bahwa strategi legitimasi bertemu dengan resistensi yang ada, khususnya dari ulama'. Kendati Sultan Agung berhasil menaklukkan kerajaan-kerajaan pantai yang didominasi ulama', tetapi ia tak sepenuhnya menguasai Jawa Tengah. Penguasaan ini tampaknya baru disempurnakan pada masa pemerintahan Amangkurat I, yang menurut beberapa sumber, memerintahkan untuk

\footnotetext{
${ }^{9}$ Saryono, "Budaya Mataram." , 28.

${ }^{10}$ A khmad Setiawan, PeilakuBirckras dalamPenganuhPahamKdkuasaanJana(Yogyakarta:Pustaka Pelajar, 1998), 38.

${ }^{11}$ Ibid. 37.

${ }^{12}$ Herusatoto, SimbdismedalamMasyarakatJana, 42.

${ }^{13}$ Selengkapnya lihat Woodward, IslamJawa, 91-2.

${ }^{14}$ Ibid.
} 
mengeksekusi lima hingga enam ribu ulama'. Hal ini kelihatannya mematahkan resistensi syariah-centris terhadap kebijakan keagamaan Mataram. Statuf relatif raja dan ulama' dalam teks, tradisi lisan dan ritual begitu sangat jelas. D alam tulisan Soebardi, dalam teks abad-19, Serat Cebddk, raja digambarkan mempunyai hak untuk mengenyampingkan ulama' dalam hal-hal yang berkaitan dengan hukum Islam. ${ }^{15}$

Islam yang berkembang di kawasan Jawa Tengah dan Kesultanan Mataram adalah Islam yang bermazhab Syafi'i. Hal ini tidak bisa dilepaskan dari sejarah munculnya Islam di Jawa. Hingga kini, terdapat empat teori masuknya Islam ke Jawa. ${ }^{16}$ Salah satu teori yang cukup kuat adalah, bahwa Islam Jawa berasal dari kawasan barat daya India, Malabar. Kerala, salah satu kawasan Malabar adalah persinggahan bagi pada pedagang dari Sumatera, Malaya dan China. D isamping memiliki kesamaan paham keagamaan, karena sama-sama bermazhab Syafi'i, juga terdapat beberapa bukti kuat bahwa adanya kesamaan arsitektur Masjid antara Kerala dan Jawa. Masjid Agung D emak, Masjid Kota G ede dan Imogiri (makam kerajaan Mataram) adalah contoh arsitektur yang mirip dengan Masjid di Kerala, yang tidak ditemui di kawasan dunia muslim lainnya. ${ }^{17}$

Pengaruh Mataram terhadap perkembangan Islam di kawasan Jawa Tengah dan Jawa Timur bagian barat sangat besar sekali. Munculnya pesantren, suatu lembaga yang kemudian berperan dalam penyebaran Islam bermazhab Syafi'i dan merupakan tempat kaderisasi elit NU, juga tidak bisa dilepaskan dari peran keraton. Munculnya pesantren pertama kali, yakni pesantren Tegalsari Ponorogo yang dipimpin oleh Kyai Muhammad Kasan Besari adalah (konon) atas inisiatif Paku Buwana II (1726-1749). Kyai Besari adalah putera menantu Paku Buwana. ${ }^{18}$ Pesantren Tegalsari merupakan cikal bakal pesantren di Indonesia. Salah satu murid kyai Besari yang populer adalah Ronggowarsito, sastrawan kraton, dan penulis babad wind hidayat jati.

Sejarah pesantren Tegalsari kemudian berlanjut dengan munculnya Pesantren Tremas Pacitan. Pesantren Tremas didirikan oleh KH. Abdul Manan (1830-1842). Ia mempunyai nama kecil Bagus Darso, putera seorang Demang dari Semanten, yaitu R. Ngabehi Dipomenggolo yang masih mempunyai hubungan darah dengan Raja Majapahit, Brawijaya V. Ia menempuh pendidikan di pesantren Tegalsari pimpinan kiai Kasan Besari (1800-1862), masa kejayaan Tegalsari. Sebagai anak Demang, ia mampu membangun pesantren cukup

\footnotetext{
${ }^{15}$ Ibid. 93.

${ }^{16}$ Teori kedatangan Islam di Indonesia; petama, Islam berasal dari anak benua India, Gujarat dan Malabaryang bermazhab Syafi'i. Mereka adalah keturunan Nabi, karena kebanyakan bergelar sayyid dan syarif. Keetua, Islam berasal dari Bengal India. Salah satu batu nisan Siti Fatimah b. Maimun di Leran Gresik memiliki kesamaan dengan batu nisan di Bengal. Ketica, Islam datang ke Indonesia berasal dari Arab. Hal ini didasarkan pada teks-teks Melayu yang ditulis oleh penulis muslim Asia Tenggara pada abad 16-17 M yang memiliki persamaan karakter dengan teks-tek A rab asli. Lihat, Azymardi Azra, JaninganUlamaTimr TengahdanKqualauanNusantaraPadaAbad XVII danXV III (Bandung:Mizan, 1994), 24-31.

${ }^{17}$ Wo odward, IsamJana, 86-7. Sumber utama sejarah muslim Kerala adalah catatan-catatan petulang Arab, Ibn Batutah pada abad 15 M. Ia mencatat, kebanyakan muslim Kerala berasal dari Arab dan kawasan Teluk lainnya yang bermazhab Syafi'i. Kerala kemudian menjadi persinggahan bagi para pedagang dari Sumetera, Malaya dan China. Pada era ini, hubungan dagang antara Kerala dengan kawasan lain di Asia Tenggara sangat intensif sekali. Tentang pengaruh muslim Kerala dan perjalanan petualang Ibn Batutah, selengkapnya bias dilihat di M.C. Ricklefs, SgarahIndonesiaModeren, ter. Satriono Wahono, dkk. (Jakarta:Serambi, 2005), 29-30.

${ }^{18}$ Lihat D ennys Lombard, Nusa Java:SilangBudaya, ter. Bagian 2 (Jakarta:G ramedia, 2005),129.
} 
luas dengan biaya sendiri.

Setelah wafat, kemudian dilanjutkan oleh puteranya, KH. Abdullah (1862-1894). Interaksi pesantren Termas dengan dunia luar banyak dilakukan oleh puteranya, yaitu kiai Mahfudz, dimana dia belajar di Mekkah, menetap di kota suci tersebut dalam waktu cukup lama yang kelak kemudian menjadi pengajar di Masjidil Haram. KH. Hasyim Asy'ari, pendiri $\mathrm{NU}$, sangat menghormati atas kealiman kiai Mahfudz. ${ }^{19}$

Sepeningal Kiai Mahfudz kemudian dilanjutkan oleh puteranya, Kiai Dimyati (18941934), sedangkan saudaranya menjadi mursyid tarekat di mana-mana. Pada era ini, Termas melahirkan tokoh-tokoh penting. Hal ini kemudian berlanjut pada era kiai Hamid D imyati (1934-1948). Pada era ini, pesantren Termas melahirkan kiai-kiai yang kelak menjadi tokoh utama di NU. Tokoh NU yang alumni pesantren Termas adalah Kiai Ma'shum (Lasem), Kiai Khaliq Hasyim (Tebuireng), Kiai Ali Ma'shum (Krapyak Yogyakarta), Kiai Mahrus Ali (Lirboyo), dan Kiai Muhammad Siraj (Surakarta). ${ }^{20}$

Sejarah Kiai Besari selalu dihubungkan dengan sejarah keislaman Adipati Batara Katong. Melalui Katong, warok Ponorogo beralkulturasi dengan kebudayaan Islam, dimana Kiai Besari memberikan andil yang cukup kuat. ${ }^{21}$ Masuknya unsur-unsur Islam ke dalam budaya Jawa semakin mempercepat pengaruh Islam di kalangan komunitas Jawa dengan memanfaatkan seni budaya sebagai "melting pot" atau titik simpul pertemuan antara budaya Islam dan Jawa.

Barangkali dapat dimaklumi jika kalangan kraton menaruh perhatian yang lebih kepada pesantren waktu itu. Setelah Amangkurat I (1645-1677), pengganti Sultan Agung memusnahkan Giri sebagai pusat Islam di kawasan Timur Nusantara yang dianggap sebagai puncak pemisahan antara dunia pesantren dan kraton, dan kemudian membunuh ribuan ulama' dan keluarganya, muncul kesadaran untuk menghidupkan kembali pesantren melalui tanah pedikan Karena menurut de Graaf, sebagaimana dikutip Taufik Abdullah, setelah Giri takluk, bukan berarti pesantren redup atau mati. Malah pesantren memiliki fungsifungsi politik yang lain, utamanya setelah dijadikan sebagai tempat perlindungan bagi keluarga kraton yang disingkirkan. ${ }^{22}$ Pesantren sebagai basis tokoh-tokoh Islam dan keluarga kraton untuk menyusun kembali strategi, atau sekedar menunjukkan kekuatan agar meningkatkan nilai tawar (bargaining position) kepada kraton.

Sementara itu, pertemuan tradisi Islam bermazhab Syafi'i dengan tradisi kraton dapat ditilik dari keterlibatan kiai dan punggawa kraton dalam Perang Diponegoro (1825-1830) melawan kolonial Belanda. Penasehat utama Pangeran Diponegoro dan yang banyak terlibat mengo barkan semangat perang adalajh Kiai Maja dari pesantren Maja, dekat D elanggu daerah Pajang yang berada dalam kekuasaan Surakarta. Kiai Maja adalah pimpinan pesantren di

${ }^{19}$ Sebagaimana dikutip Hanun Asrohah dalam, "Pelembagaan Pesantren:A sal-Usul dan Perkembangan Pesantren di Jawa”, (D isertasi D oktor, IAIN Syarief Hidayatullah, Jakarta, 2002), 290. Periksajuga Martin van Bruinessen, KitabKuningPesantrendanTarkkat, ter. (Bandung:Mizan, 1995), 145.

${ }^{20}$ Ibid. Wawancara, 21 O ktober 2008.

${ }^{21}$ Tentang prosses pertemuan tradisi Islam dengan budaya Jawa di kalangan masyarakat pedalaman, selengkapnya lihat M. Hariwijaya, IdamKgiawen(Yogyakarta:G elombang Pasang, 2006) 180-185.

${ }^{22}$ Taufik Abdullah, "Islam dan Pembentukan Tradisi di AsiaTenggara;Sebuah Perspektif Perbandingan", dalam Taufik Abdullah dan Sharon Shiddique (ed.), Tradis dan KdъangkitanIdamdi AsiaTenggara(Jakarta:LP3E S, 1988), 88-91. 
daerah perdikan Baderan. G uru-guru agama di pesantren Maja mempunyai hubungan akrab dengan keluarga kraton Surakarta dan Yogyakarta. Banyak bangsawan kraton yang memondokkan keluarganya di Kyai Maja. ${ }^{23}$

Selain pesantren Baderan juga ada pesantren di Madiun yang ikut perang D iponegoro. Pada abad 18 M, di Karesidenan Madiun terdapat pesantren Tegalsari, pesantren di daerah perdikan Banjarsari Madiun dan pesantren di desa perdikan Sewulan Madiun. Tidak kurang dari 42 sekolah agama terlibat dalam perang Diponegoro, dengan 88 kiai, 36 haji, 11 shiekh, 18 pejabat keagamaan (kiai penghulu, khotib, modin, juru kunci), 15 guru agama dan pimpinan pesantren di Bagelen, Kedu, Mataram, Madiun dan Pajang. ${ }^{24}$

Pertemuan kembali kalangan kraton dengan pesantren yang ditandai dengan munculya Pesantren Tegalsari Ponorogo dan pesantren-pesantren di Karesidenan Madiun menguatkan dugaan adanya balas budi atas dosa masa lalu, utamanya pada masa Amangkurat I. Hubungan kraton dan pesantren menurut Taufik dapat dimaknai sebagai pergantian ritme "gempur" dan "akur" (rat and rally). Artinya ada saat-saat tertentu kedua belah pihak "bertengkar", tetapi ada saatnya mereka "mesra" ${ }^{25}$ Namun demikian ritme itu harus dipahami dari kaca mata tradisi politik, bahwa siapa pun yang melawan otoritas harus dilawan meskipun mereka adalah wali atau kiai. Kondisi konflik hanyalah sebuah tradisi. Menurut Taufik, tradisi ini juga mencita-citakan hubungan yang serasi antara dua varian dari dunia politik dan budaya yang sama. Inilah tradisi yang tidak pernah alpa dalam mengusahakan hubungan yang erat antara yang mewakili penguasa yang sah, atau thelegal power, menurut Parry, dengan ulama yang menjadi theauthority power. ${ }^{26}$

Tradisi "gempur" dan "akur" merupakan tradisi "akomodatif" yang merupakan salah satu ciri tradisi politik sunni, dimana tradisi ini sudah menguat sejak D emak masih berkuasa. Pemerintahan yang tidak mengganggu atau memberikan kebebasan kepada umat Islam untuk menjalankan ibadah merupakan pemerintahan yang sah dan wajib ditaati oleh umat Islam, meskipun pemerintahan tersebut bukan beragama Islam. Hal ini yang dilakukan oleh ulama kepada kerajaan Mataram sebagai pemerintah yang sah tanpa melakukan konfrontasi terhadapnya. Strategi "jalan damai" tersebut kemudian menjadi ciri utama dalam tradisi politik sunni yang berhaluan Ahlussumahmaljamaah yang berkembang di Indonesia.

\section{Orientasi Politik; Personal dan Ekslusif}

D alam konteks masyarakat Islam Jawa Timur, hibridasi berjalan sangat panjang dan berlangsung cukup lama, baik hibridasi struktural maupun kultural. Islam Mataraman yang membentang dari Jombang bagian Barat hingga Madiun di bagian barat merupakan perpaduan antara budaya Hindu, Jawa dan Islam dengan segala karakter dan peradaban yang berbeda dengan kebanyakan muslim Jawa Timur. Pengaruh kerajaaan Mataram Islam yang cukup besar tidak dapat dapat dipungkiri dalam komunitas tersebut. Menurut Woodward" ${ }^{27}$, kawasan

\footnotetext{
${ }^{23}$ Hanun Asrohah, Pdembagaan Pesantren;Asal-Usul dan pekenbangan Pesantren di Java (Jakarta:D epag RI, 2004), 195.

${ }^{24}$ KH. D imyati, Wavanara, 200 ktober 2008.

${ }^{25}$ Taufik A bdullah, "Islam dan Pembentukan Tradisi, 91.

${ }^{26}$ Ibid. Lihat juga Parry, Pditical Elites 68.

${ }^{27}$ Mark R. Woodward, IsamJava Kesalehan Nomatif Vesus Kebatinan, ter. Hairus Salim HS (Yogyakarta:LK iS, 2006), 354.
} 
tersebut disebut unik bukan karena ia mempertahankan aspek-aspek budaya dan agama pra-Islam, melainkan karena konsep-konsep sufi mengenai kewalian, jalan mistik dan kesempurnaan manusia diterapkan dalam formulasi suatu kultus keraton (impeial ailt). Pada gilirannya, agama negara itu merupakan suatu model konsepsi jawa tradisional mengenai aturan sosial, ritual, dan bahkan aspek-aspek kehidupan sosial seperti bentuk-bentuk kepribadian, hati dan penyakit.

Karena itu, teks-teks, mitos-mitos dan pernyataan-pernyataan ideologis lainnya memberikan akses yang mempunyai hak-hak istimewa terhadap organisasi dan cara kerja sistem dari pengetahuan budaya. Di sini, teori Jawa, yang sering disebut oleh elite NU Mataraman mengenai ratu adil memberikan contoh yang meyakinkan. Sultan Mataram, dalam teori merupakan manusia sempurna yang dibimbing langsung oleh kehendak Allah, dan mampu menjamin kemakmuran, kekuasaan dan spritualitas seluruh rakyatnya. Konsep ini mempunyai pengaruh terhadap budaya Jawa, meskipun doktrin ini tidak berhasil. Tetapi bagaimanapun, peredarannya secara umum di dalam masyarakat Jawa memperkembangkan instabilitas karena Sultan tidak bisa mendekati ideal yang mereka dan orang-orang lain yakini merupakan suatu harapan normatif. Tidak ada tempat lain dimana konflik antara idealideal kultural dan realitas sosial ini terekspresikan lebih jelas daripada di dalam gerakan ratu adil kontemporer dan historis, yang memprediksikan kebangkitan ratu adil yang akan mematahkan ideal tersebut sebagai realias sosial.

Sementara dalam tradisi Mataraman, orkestra politik cenderung statis. Pengaruh Mataram dan sufisme yang dianut oleh Kraton sangat menonjol dibandingkan dengan kawasan lain di Jawa Timur. Agama sufi yang menjadi ciri khas Kraton dijadikan sebagai dasar untuk menjelaskan, menyusun dan memberi makna terhadap berbagai aspek dalam kehidupan. Semua itu mirip dengan apa yang disebut Martin (1987), sebagai subtekstual (subtextual assumptions) ${ }^{28}$, dan dari subjek itu sendiri merupakan rangkaian dasar dari penafsiran di Jawa dan di dunia muslim secara keseluruhan. Bagaimanapun di kalangan Islam Mataraman, cara menafsirkan dan menerapkan aksioma-aksioma ini mempunyai pengaruh pada bagaimana aspek-aspek kebudayaan politik dan keagamaan dipahami.

Proses penafsiran ini menghasilkan dua bentuk dasar religiusitas, masing-masing mempunyai rangkaian luas dari berbagai varian yang bersifat personal, berbasis kelas dan regional. Secara umum Islam Jawa mengharuskan agar ritus-ritus peralihan kehidupanseperti khitanan, perkawinan, kematian dilaksanakan dengan menggunakan hukum Islam, tetapi juga berpegang pada apsek lain dari kesalehan yang syariatnya merupakan suatu hal bebas-pilih. Di dalam dua hal ini, oleh Woodward $(2005)^{29}$ penerapan mikrokosmos dan makrokosmos ke dalam pemikiran kosmologis, keagamaan, sosial dan politik menstransformasikan watak mistisme sufi Jawa. Secara umum, sufisme merupakan agama yang sangat pribadi. Fokusnya adalah hubungan antara mistik individual dan Allah. Di kawasan Mataraman, struktur jalan mistik memainkan peran dalam pemikiran sosial dan politik tradisional.

\footnotetext{
${ }^{28}$ Sebagaimana dikutip oleh Muhtadi, Asep Saiful, Kommikas Pditik Nahdlatul Ulama'. (Jakarta:LP3E S, 2004), 237.

${ }^{29}$ Woodward, IsamJama, 114-5.
} 


\section{Penutup}

Islam Mataraman merupakan Islam yang bercorak khas dan berbeda dengan Islam yang berkembang di Indonesia, utamanya di Jawa Timur. Islam Mataraman terbentuk dari proses dialektika yang panjang antara budaya Jawa, kerajaan Mataram dan Islam yang ketiganya saling mengisi dan meneguhkan. Karena bentuknya yang khas dan berbeda itulah, tradisi Islam memperoleh tempat yang berbeda pada masyarakat tersebut.

Ciri dan karakteristik yang melekat pada tradisi kehidupan masyarakat juga berimplikasi pada budaya politiknya. Dalam sejarah perpolitikan dan Pemilu di Indonesia, muslim Mataraman menempatkan kekuatan politik yang personal dan kohesif, serta memberlakukan politik sebagai ajang untuk mengejewantahkan paham riligius Jawa yang berorientasi pada macocosmosdan mocoosmos Tidak seperti kawasan lain di Jawa Timur dimana loyalitas personal lebih menguat dibandingkan dengan loyalitas institusional, muslim Mataraman mengindahkan semua aspek tersebut. D alam konteks inilah kecenderungan lebih rasional dalam berpolitik lebih mengemuka dibandingkan dengan emosional.

\section{DAFTAR PUSTAKA}

Abdullah, M. A min. Studi Agama; Nomativitas atau Histaisitas Yogyakarta: Pustaka Pelajar, 1996.

Abdullah, Taufik dan Sharon Shiddique (ed.). Tradis dan Kdbangkitan Idamdi Asia Tenggara Jakarta: LP3ES, 1988.

Asrohah, Hanun. Pdenbagaan Pesantren; Asal-Usul dan pekembangan Pesantren di Java. Jakarta: Depag RI, 2004.

Azra, Azymardi. Jaincan Ulama Timur Tengah dan Kepualauan Nusantara Pada AbadXV II dan XVIII. Bandung: Mizan, 1994.

Bruinessen, Martin van. Kitab KuningPesantren dan Tarkkat. ter. Bandung: Mizan, 1995.

Hariwijaya, M. Isam Kjawen Yogyakarta: Gelombang Pasang, 2006.

Lombard, D ennys. Nusa Jana:Silang Budaya, ter. Bagian 2. Jakarta: G ramedia, 2005.

Muhtadi, A sep Saiful, Kommikasi Pditik Nahdatul Ulama'. Jakarta: LP3ES, 2004.

Mulder, Niels. MistisismeJawa; Idedog di Indonesia, ter. Noor Cholis. Yogyakarta: LkiS, 2001. - - - . Ruang Batin Masyarakat Indonesia, terj. Wisnu Hardana. Yogyakarta:LKiS, 2001.

Ricklefs, M.C. Sgarah Indonesia Modken, terj. Satriono Wahono, dkk. Jakarta: Serambi, 2005.

Setiawan, A khmad. Peilaku Birdkrasi dalam Penganuh Paham Kdkuasaan Java. Yogyakarta: Pustaka Pelajar, 1998.

Sutarto, Ayu dan Setya Yuwana Sudikan (ed.), Pentaan Keaudayaan Prqpind Java Timr;Seduah Upaya Pencarian Nilai-Nilai Positif Jember: Biro Mental Propinsi dan Kompyawisda Jatim, 2008.

Syam, Nur. "Islam Pesisiran dan Islam Pedalaman; Tradisi Islam di Tengah Perubahan Sosial", (Makalah tidak diterbitkan), www.ditpertais.net

Woodward, Mark R. IsamJama Kesaldhan Nomatif Vessus Kdbatiman ter. Hairus Salim HS Yogyakarta: LKiS, 2006. 